\title{
Brief
}

\section{Off-pump management of aortic arch aneurysm by using an endovascular thoracic stent graft}

\author{
Charles A. Dietl, MD, ${ }^{a}$ Karthikeshwar Kasirajan, MD, ${ }^{\text {b }}$ Stuart B. Pett, MD, and Jorge A. Wernly, MD, ${ }^{\text {a }}$ Albuquerque, NM
}

See related articles on pages 1184 and 1186.
From the Divisions of Cardiothoracic Surgery $^{\mathrm{a}}$ and Vascular Surgery, ${ }^{\mathrm{b}}$ Department of Surgery, University of New Mexico Medical Center, Albuquerque, NM.

Received for publication Sept 14, 2002; accepted for publication April 30, 2003.

Address for reprints: Charles A. Dietl, MD, Department of Surgery, University of New Mexico Medical Center, 2211 Lomas Blvd, NE, ACC-2, Albuquerque, NM 871315341 (E-mail: CDietl@salud.unm.edu).

J Thorac Cardiovasc Surg 2003;126:1181-3

Copyright $(\odot) 2003$ by The American Association for Thoracic Surgery

$0022-5223 / 2003 \$ 30.00+0$

doi:10.1016/S0022-5223(03)00722-0
$\mathrm{W}$

e report 2 patients who underwent aortic arch reconstruction without cardiopulmonary bypass.

\section{Clinical Summaries}

PATIENT 1. A 68-year-old man with a past history of ascending aortic replacement for a type A aortic dissection in 1991 presented in February 2001 with back pain and exertional dyspnea. Computed tomographic (CT) scanning revealed a $6.5 \times 9-\mathrm{cm}$ aneurysm of the distal aortic arch. Risk factors included chronic obstructive pulmonary disease, oxygen dependence, poor ventricular function, and renal insufficiency. Endovascular stent grafting of the distal aortic arch was considered as an alternative approach. However, a preoperative angiogram (Figure 1, A) demonstrated a lack of adequate proximal landing zone for the thoracic stent graft. Thus we recommended reimplantation of the innominate and left common carotid arteries to the ascending aortic graft, followed by endovascular stent grafting of the entire aortic arch, which would not require the use of cardiopulmonary bypass (Figure 2).

A redo sternotomy incision was used for exposure. The aortic arch aneurysm was not dissected. After administering 10,000 units of heparin, a partial occlusion clamp, reinforced with Teflon felt on the clamping surface, was applied on the ascending aortic graft. The clamp was placed as low as possible to allow an adequate landing zone for the thoracic stent graft in the distal part of the ascending aortic graft. Cardiac function was constantly monitored by means of transesophageal echocardiography.

A 12-mm Hemashield graft was anastomosed proximally to the ascending aortic graft and distally to the divided end of the innominate artery. A separate 7-mm Hemashield graft was anastomosed proximally to the $12-\mathrm{mm}$ graft and distally to the divided end of the left common carotid artery (Figure 2). Both distal anastomoses were done sequentially, without a shunt.

The thoracic stent graft (W. L. Gore \& Associates, Inc, Flagstaff, Ariz; Medtronic, Santa Rosa, Calif) was custom designed. The diameter of the thoracic stent graft was $28 \mathrm{~mm}$, approximately $20 \%$ greater than the ascending aortic graft diameter $(24 \mathrm{~mm})$, to achieve optimal friction seal. The stent graft was introduced through a femoral artery cut down. The proximal landing zone was the distal end of the ascending aortic graft. The stent graft was balloon dilated after deployment to optimize graft fixation. The left subclavian artery was ligated through a separate left supraclavicular incision to avoid retrograde filling of the aneurysmal sac. Completion aortography confirmed complete aneurysm exclusion (Figure 1, $B)$.

The postoperative course was uneventful. There were no signs of upper limb ischemia caused by ligation of the left subclavian artery. A follow-up CT scan obtained 7 months later demonstrated complete thrombosis of the aneurysmal sac. Relatives informed us that while the patient was out of state, he died of pneumonia 12 months after the operation. No autopsy was obtained. 

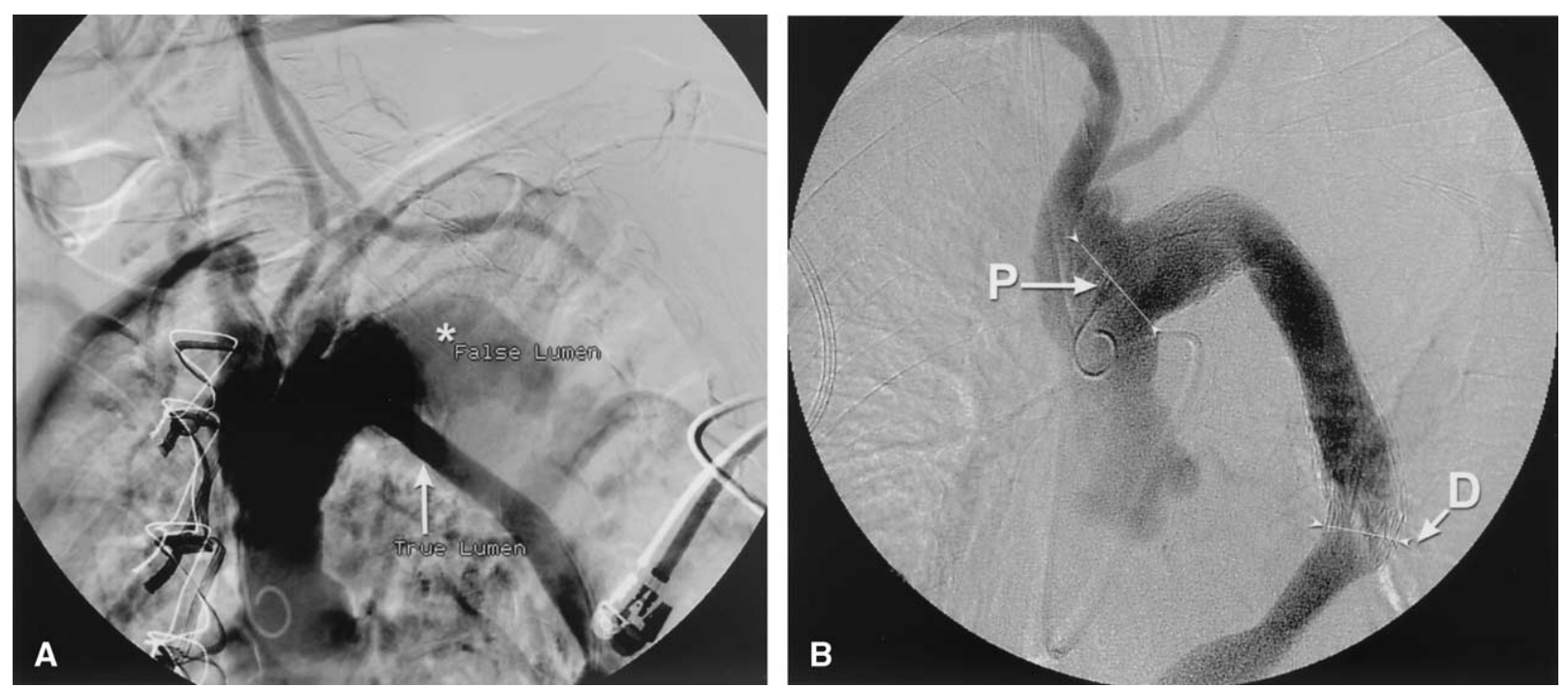

Figure 1. A, Preoperative angiogram of patient 1 demonstrating an aortic aneurysm in close proximity with the origin of the left subclavian artery. B, Postoperative angiogram of patient 1 showing complete exclusion of the aneurysm with the thoracic stent graft within the aortic arch and the innominate and left common carotid arteries reimplanted in the ascending aortic graft. $D$, Distal end of the stent graft; $P$, proximal end of the stent graft.

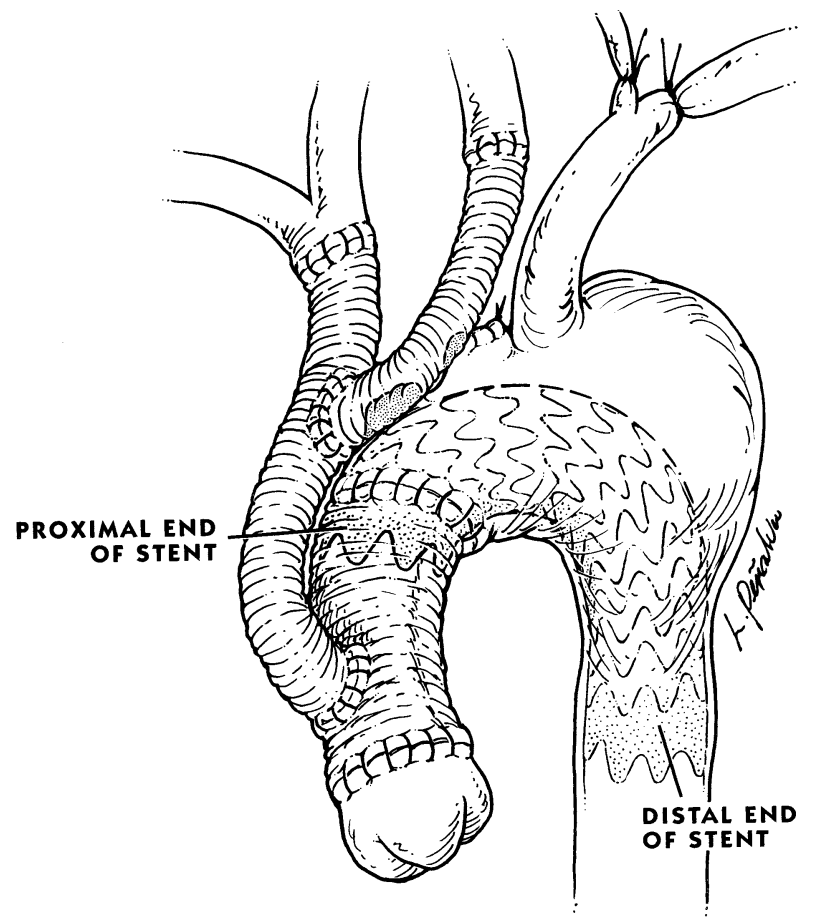

Figure 2. Diagram of final aortic arch reconstruction showing the endovascular stent graft extending from the distal end of the ascending aortic graft to the middescending thoracic aorta. The left subclavian artery was ligated.

PATIENT 2. A 46-year-old man, having had ascending aortic replacement for a type A aortic dissection in April 2001, presented with interscapular pain in December 2001. Preoperative angiogra- phy revealed a $6.5-\mathrm{cm}$ aneurysm of the distal aortic arch involving the origin of the left subclavian and left common carotid arteries (Figure 3, A). There was no aortic regurgitation, despite the presence of dilated sinuses. Conventional surgical resection with cardiopulmonary bypass and deep hypothermic circulatory arrest versus off-pump aortic arch reconstruction and endovascular stent grafting were offered as alternate approaches. The patient opted for the second option because of fear of neurologic complications. The technique used was identical to the one described for patient 1 . Postoperative angiography confirmed complete exclusion of the aneurysm, and no aortic regurgitation was seen (Figure $3, B$ ). His recovery was uneventful. Follow-up CT scans obtained at 6 and 12 months revealed that the aneurysmal sac was completely thrombosed, except for a small communication between the descending thoracic aorta and the distal false lumen.

\section{Discussion}

Two major issues concerning operations for aortic arch aneurysms are the significant incidence of neurologic complications and mortality rates, especially if the circulatory arrest time exceeds 40 minutes. ${ }^{1}$ Permanent neurologic damage can result from interruption of cerebral circulation or embolization of atherosclerotic debris. $^{2}$

Kazui and colleagues ${ }^{3}$ reported substantially reduced in-hospital mortality and an exceptionally low incidence of neurologic complications with selective antegrade cerebral perfusion. Their outstanding results, however, are uncommon, particularly in elderly high-risk patients.

Recently, several authors have advocated treating distal aortic arch aneurysms with endovascular stent grafts implanted through sternotomy incisions using cardiopulmonary bypass and deep hypothermic circulatory arrest. ${ }^{4,5}$ Buth and associates ${ }^{6}$ reported a case of endovascular implantation of a stent graft to exclude a 

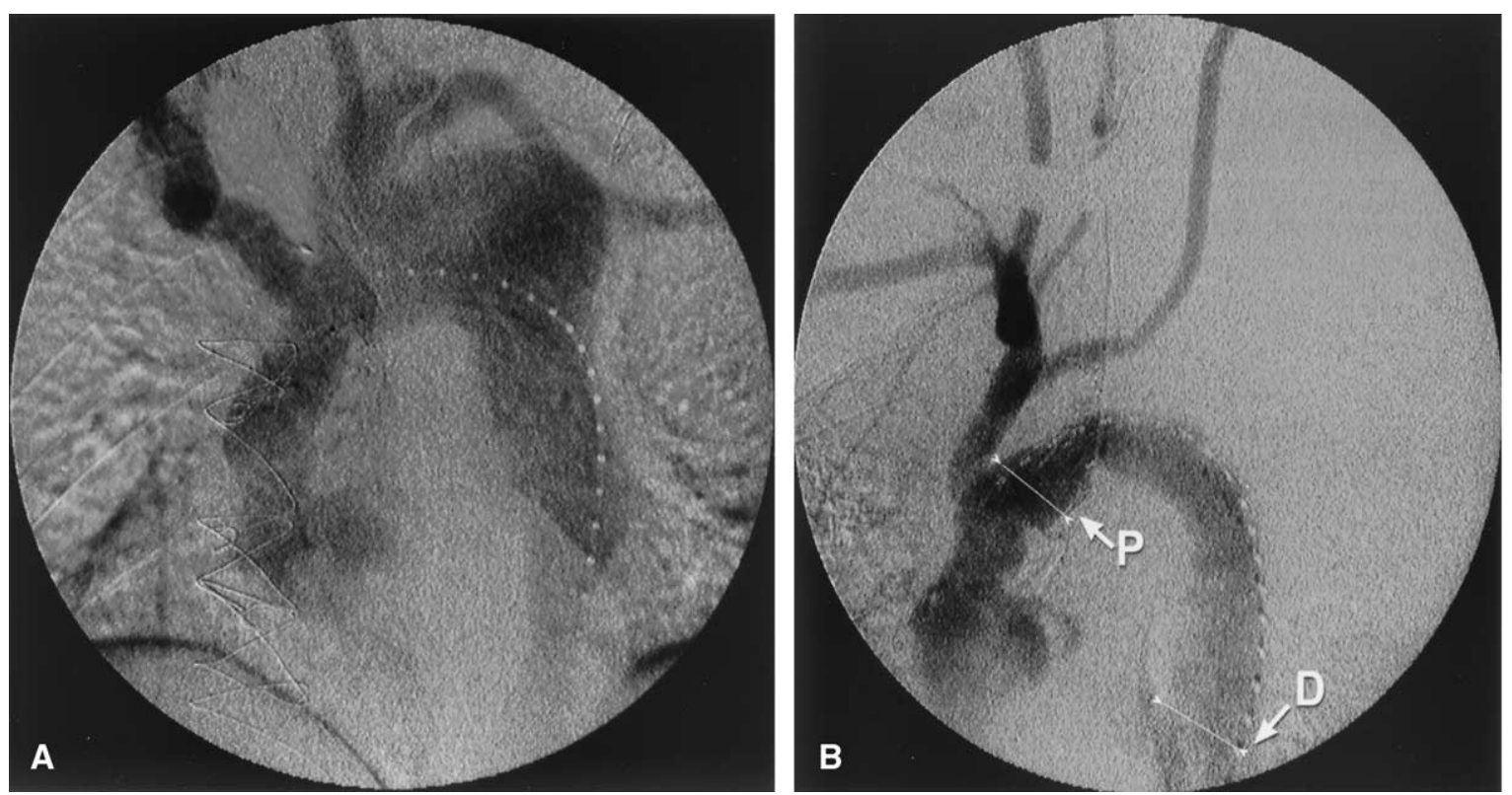

Figure 3. A, Preoperative angiogram of patient 2 demonstrating the distal arch aneurysm involving the origin of the left subclavian and left common carotid arteries. B, Postoperative aortogram of patient 2 confirming complete exclusion of the aneurysm and proximal reimplantation of the innominate and left common carotid arteries. $D$, Distal end of the stent graft; $P$, proximal end of the stent graft.

distal aortic arch aneurysm combined with partial aortic arch reconstruction without cardiopulmonary bypass.

To our knowledge, there are no reports in the literature of endovascular implantation of a stent graft to exclude the entire aortic arch combined with total aortic arch reconstruction without use of cardiopulmonary bypass or deep hypothermic circulatory arrest. One of the technical problems that might occur with the operation we describe is that the curvature of the aortic arch could cause a kink in the midportion of the stent graft. Both patients had postdeployment balloon dilatation to eliminate graft kinking to overcome this potential complication. In conclusion, proximal reimplantation of the aortic arch vessels combined with an endovascular stent graft to exclude the entire aortic arch without using cardiopulmonary bypass is an attractive treatment option for aortic arch aneurysms, especially in high-risk patients. Longterm follow-up is necessary before making any definitive conclusions.

We thank Lisa Peñalver, BA, medical illustrator (Peñalver Illustration and Design, Fairbanks, Alaska) for providing the artistic illustration.

\section{References}

1. Svensson LG, Crawford ES, Hess KR, Coselli JS, Raskin S, Shenaq SA, et al. Deep hypothermia with circulatory arrest. Determinants of stroke and early mortality in 656 patients. J Thorac Cardiovasc Surg. 1993; 106:19-31.

2. Griepp RB. Cerebral protection during aortic arch surgery. J Thorac Cardiovasc Surg. 2001;121:425-7.

3. Kazui T, Washiyama N, Muhammad BAH, Terada H, Yamashita K, Takinami M. Improved results of atherosclerotic arch aneurysm operations with a refined technique. J Thorac Cardiovasc Surg. 2001;121: 491-9.

4. Usui A, Tajima K, Nishikimi N, Ishiguchi $\mathrm{T}$. Implantation of an endovascular covered stent-graft for distal aortic arch aneurysm via midsternotomy under pigtail catheter guidance. Eur J Cardiothorac Surg. 1999;16:356-8.

5. Iguro Y, Arata K, Yamamoto H, Masuda H, Sakata R. A new concept in distal arch aneurysm repair with a stent graft. $J$ Thorac Cardiovasc Surg. 2002;123:378-80.

6. Buth J, Penn O, Tielbeek A, Mersman M. Combined approach to stent-graft treatment of an aortic arch aneurysm. J Endovasc Surg. 1998;5:329-32. 